\title{
MODELAGENS MATEMÁTICA E FÍSICA DO ESCOAMENTO DO AÇO LÍQUIDO EM DIFERENTES PROJETOS DE DISTRIBUIDOR DO LINGOTAMENTO CONTÍNUO DA USIMINAS
}

Fabiano Almir Barbosa (1)

Glailson Mattos de Araújo Filho (1)

Roberto Parreiras Tavares (2)

\section{Resumo}

As exigências de maior produtividade e de melhoria da qualidade dos produtos têm motivado alterações no projeto dos distribuidores utilizados no processo de lingotamento contínuo de aço. Neste estudo, é desenvolvido um modelo matemático para a simulação do escoamento tridimensional turbulento do aço líquido, com a finalidade de avaliar a influência da alteraçăo do fundo do distribuidor e da utilização do inibidor de turbulência no perfil de escoamento do aço. Este modelo utiliza os recursos do software ANSYS/FLOTRAN e sua validação é realizada por meio de experiências em modelo físico. A utilização do inibidor de turbulência em conjunto com a prática de elevação do fundo do distribuidor permitiu uma melhoria significativa nas condiçöes de escoamento do aço e aumento do tempo de residência, comparados aos valores obtidos com o projeto do distribuidor atualmente em uso.

Palavras-chave: Escoamento; Distribuidor do lingotamento contínuo; Modelagens matemática e física.

\section{Mathematical and Physical Modelling of Steel Flow in Different Tundish Desings at Usiminas Continuous Casting}

\begin{abstract}
Demands for larger productivity and improvement on products quality have been motivating the tundish design modification. A mathematical model in order to simulate the turbulent three-dimensional steel flow in a tundish system at Usiminas works, using the ANSYS/FLOTRAN software is developed. The purpose is to evaluate the influence of the tundish floor design, and the use of the turbulence inhibitor on the fluid flow. Experiments in physical model, using the same conditions as those of the mathematical model is also carried out to validate the mathematical model. The use of the turbulence inhibitor together with the practice of the tundish floor elevation improved the fluid flow pattern, when compared to the nowadays tundish design.
\end{abstract}

Key-words: Fluid flow. Continuous casting tundish. Mathematical and physical models.

\section{INTRODUÇÃO}

O distribuidor ganhou considerável importância devido à ênfase contínua na produção de aços de melhor qualidade, levando ao desenvolvimento da metalurgia do distribuidor.

Atualmente, o distribuidor é projetado com a finalidade de possibilitar a realização de várias operaçōes metalúrgicas, tais como separação e flotaçẫo de inclusôes, ajuste fino de composiçẫo química do aço, modificação da morfologia das inclusões formadas, controle do superaquecimento e homogeneização térmica e química do aço.
Procura-se também utilizar, no lingotamento contínuo, um projeto de distribuidor que proporcione uma menor geração de sucata de aço ao final do lingotamento, aumente o rendimento da produção de placas, diminua o volume de mistura presente numa troca de qualidade e facilite a operaçăo de remoção do aço e da escória remanescentes nesse reator.

Para alcançar esses objetivos procura-se aperfeiçoar o projeto do distribuidor, modificando seu fundo, e utilizar inibidores de turbulência visando modificar o fluxo de aço líquido para criar condiçôes favoráveis à eliminação de inclusōes.

As técnicas utilizadas para o desenvolvimento de um projeto de distribuidor de lingotamento contínuo são as modelagens física e matemática. A primeira utiliza água para

\footnotetext{
(1) Membro da ABM, Engenheiro Metalurgista, M.C., Centro de Pesquisa e Desenvolvimento da Usiminas; Ipatinga-MG.

(2) Membro da ABM, Engenheiro Metalurgista, Dr., Professor Adjunto do Departamento de Engenharia Metalúrgica e de Materiais da EEUFMG; Belo Horizonte-MG.
} 
simular o aço líquido e a segunda aplica métodos de elementos ou volumes finitos, com o uso de softwares e computadores de alto desempenho para obter a solução das equações diferenciais tridimensionais que representem o escoamento.

Neste trabalho, as duas técnicas são utilizadas para avaliar diferentes projetos de distribuidor. $O$ modelo matemático desenvolvido utiliza o software ANSYS/FLOTRAN, para avaliação e otimização de parâmetros ligados ao escoamento do aço líquido, tais como o tempo de residência médio, o tempo de residência mínimo e as fraçōes de volume morto, pistonado e de mistura. Este modelo é validado com a técnica de modelagem física de processos, utilizando como base a geometria do distribuidor das Máquinas de Lingotamento Contínuo I e 2 da Usiminas - Usina Siderúrgica de Minas Gerais.

\section{METODOLOGIA}

\section{I Formulação matemática}

O modelo matemático considera:

- escoamento tridimensional e turbulento;

- superfície do banho plana e móvel;

- formação de ondas e presença de escória na superfície livre ignoradas;

- escoamento macroscopicamente estacionário;

- arraste de ar e escória pelo jato de aço na entrada desprezado;

- fluido newtoniano e incompressível; e

- sisterna isotérmico.

O projeto de distribuidores envolve obrigatoriamente conceitos da mecânica dos fluidos, visto que o movimento do fluido no distribuidor, o comportamento da entrada de gases e o comportamento das partículas de inclusôes são regidos pelas leis do escoamento dos fluidos.

A descrição matemática do escoamento do aço líquido no distribuidor envolve as equaçōes de continuidade, de conservação de momento (equaçốes de Navier-Stokes), de conservação da energia cinética turbulenta e de conservação da taxa de dissipação dessa energia. Essas equaçôes diferenciais são expressas, considerando estado estacionário, na seguinte forma geral:

$$
\frac{f}{f x_{j}}\left(\rho u_{j} \phi\right)=\frac{f}{f x_{j}}\left(\Gamma_{\phi} \frac{f \phi}{f x_{j}}\right)+S_{\phi}
$$

em que:

$x_{\mathrm{j}}$ representa as coordenadas cartesianas;

u representa os componentes da velocidade média turbulenta;

$\phi$ é a variável dependente (uj, k e e);

k é a energia cinética turbulenta;

$\varepsilon$ é a taxa de dissipação da energia cinética turbulenta;

$\Gamma_{\phi}$ é o coeficiente efetivo de difusão para f; e

$\mathrm{S}_{\phi}$ é o termo fonte para $\mathrm{f}$.
Além das equações do modelo de turbulência k-e (') adiciona-se a equação de conservação de massa convecçâa-difusão para a injeção de traçadores, a fim de representar o fenômeno da adição do traçador. Essa equação, com base no sistema de coordenadas cartesianas, é expressa como:

$$
\rho\left[\frac{f C_{i}}{f t}+\sum \frac{f}{f x_{j}}\left(u_{j} C_{i}\right)\right]=D_{e f}\left[\sum \frac{f^{2} C_{i}}{f x_{j}^{2}}\right]
$$

em que, $C_{i}$ representa a concentração do traçador em cada instante $i$ e $D_{\text {ef }}$ a difusividade efetiva, ou seja, a soma das difusifidades mole-cular e turbulenta.

A equação de convecção-difusão apresentada é resolvida após a obtenção de perfis de velocidade e grandezas de turbulência no interior do distribuidor.

\subsection{Condições de Contorno}

A solução das equações diferenciais descritas anteriormente é obtida para as seguintes condiçốes de contorno:

- em todas as superfícies sólidas, incluindo os dispositivos de controle de fluxo (barragens, diques e inibidor de turbulência), são consideradas condições de não-deslizamento; - na superfície livre e nos planos de simetria, o componente da velocidade normal ao plano e as variações de todas as outras propriedades em relação à direção normal são nulas; $\mathrm{e}$

- na região de entrada do distribuidor, especifica-se o componente de velocidade perpendicular a essa região em função da vazão volumétrica do fluido e da área da seção transversal da válvula longa. Além disso, devido ao escoamento turbulento, definem-se valores da energia cinética turbulenta, $k$, e da taxa de dissipação dessa energia, e, nessa região.

Para estabelecer as condiçōes de contorno na região de saída do distribuidor, utiliza-se uma pressão relativa fixa e igual a zero.

Após a obtenção do perfil de escoamento para o regime permanente, é ativado o algoritmo transiente e aplicada a condição de contorno inicial para a equação de convecção-difusão incorporada ao modelo. Na regiâo de entrada, considera-se a concentração do traçador igual a 0,0 I g.mL-1 durante o período de injeção no distribuidor (técnica de pulse input) e $0 \mathrm{~g} \cdot \mathrm{mL}^{-1}$ após o término deste período. 

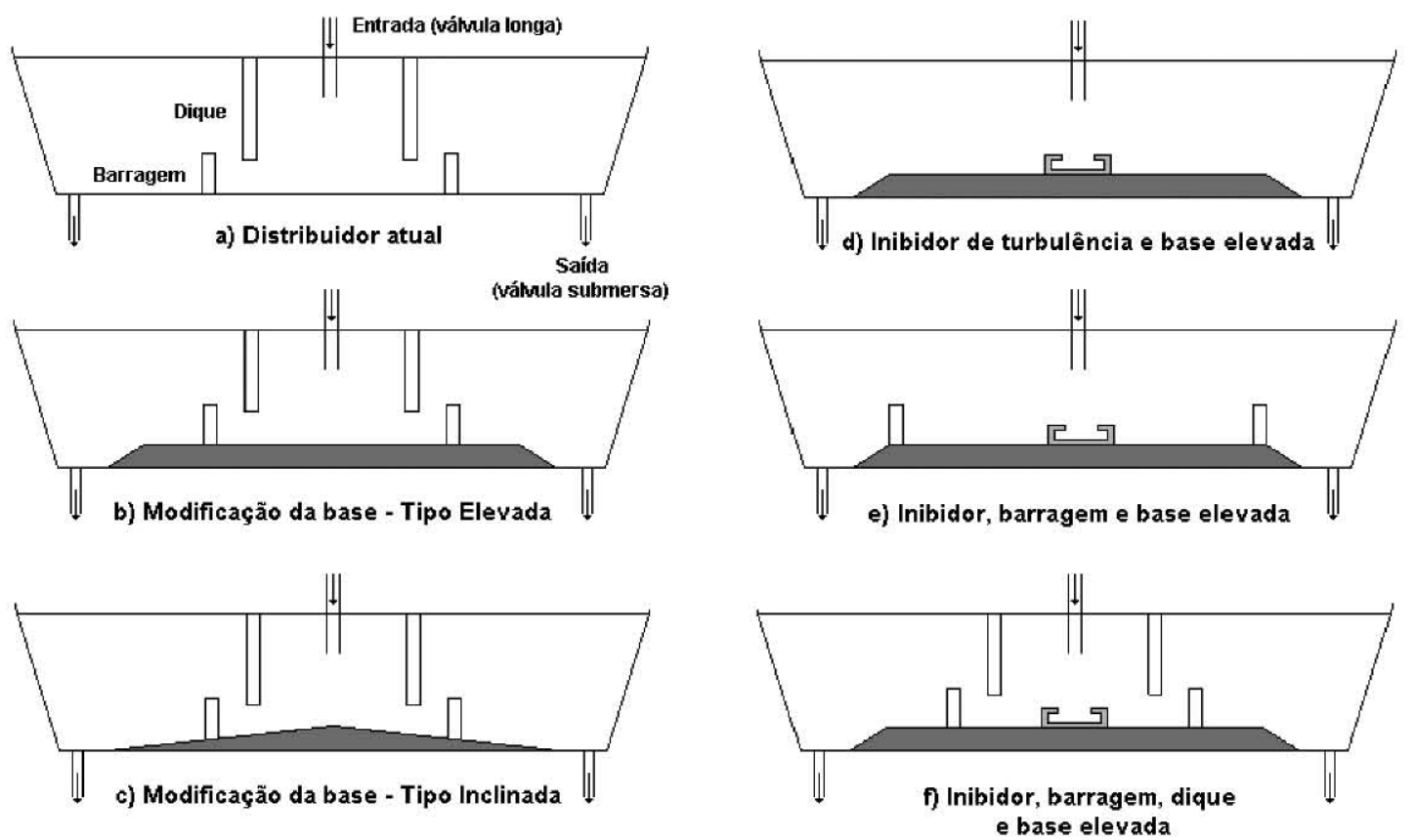

Figura I. Visão esquemática das al teraçōes realizadas no projeto do distribuidor: a) distribuidor atual; b) modificação da base - tipo elevada; c) modificação da base - tipo inclinada; d) inibidor de turbulência e base elevada; e) inibidor de turbulência, barragem e base elevada; e f) inibidor de turbulência, barragem, dique e base elevada.

\subsection{Alteraçóes Realizadas no Projeto do Distribuidor}

As principais modificações realizadas no projeto atual do distribuidor foram a alteração de seu fundo plano e a utilização do inibidor de turbulência como um dispositivo controlador de fluxo de aço líquido. Essas alterações podem ser vistas esquematicamente na Figura I.

Devido à simetria geométrica e à simetria verificada nas condiçôes de contorno, somente _ do distribuidor foi simulado, o que permite uma considerável redução nos esforços computacionais.

\subsection{Método Numérico}

O sistema de equaçôes diferenciais parciais, composto foi: equação de continuidade, equações de Navier-Stokes, equações de turbulência e equação de convecção-difusão, pode ser resolvido pelos recursos existentes no software ANSYS/FLOTRAN, que utiliza a técnica de elementos finitos.

A discretização do domínio físico tridimensional, definido pelo distribuidor, é realizada em uma malha hexaédrica. Foram desenvolvidas algumas simulaçồes preliminares buscando determinar o tamanho adequado da malha, para se obter soluçốes que não variassem com o refinamento das malhas usadas nas soluçóes das equações diferenciais. Utilizou-se uma malha não uniforme com $23 \times 40 \times 136$ nós (direçôes $x_{1}, x_{2}$ e $x_{3}$, respectivamente) para os projetos de distribuidor sem inibidor de turbulência, e uma malha não uniforme com 29x64x l46 nós, para os projetos com inibidor de turbulência.

A solução do modelo matemático proposto é considerada convergente quando a diferença média entre duas iteraçôes consecutivas atinge um valor da ordem de $10^{-4}$ para uma dada variável genérica f. $\mathrm{Na}$ equação transiente, ou seja, na equação de convecção-difusão, adota-se um incremento de tempo correspondente a $0,1 \mathrm{~s}$. Foi aplicada sub-relaxação em todas as variáveis dependentes com o objetivo de facilitar a convergência.

\subsection{Validação do Modelo Matemático}

Para validar o modelo numérico desenvolvido, foram realizadas experiências em modelos físicos dos distribuidores das Máquinas de Lingotamento Contínuo I e 2 da Usiminas. Esses modelos foram projetados e construídos na escala de $\mathrm{I}: 3$. Como esses modelos foram construídos em escala reduzida, não foi possível satisfazer simultaneamente os critérios de similaridade de Reynolds e de Froude. Neste estudo, adota-se o critério de similaridade de Froude para avaliar o escoamento.

\section{RESULTADOS E DISCUSSÃO}

A visualização dos campos de velocidade resultantes obtidos nas simulações numéricas torna-se um pouco difícil devido ao fato de o modelo ser tridimensional e à alta densidade da malha 
de elementos finitos utilizada. Para facilitar essa visualização, alguns planos são escolhidos para ilustrar os resultados obtidos. As Figuras 2 e 3 aprsentam, parcialmente, os campos de velocidade resultante obtidos, na forma vetorial, para algumas das simulaçōes realizadas.
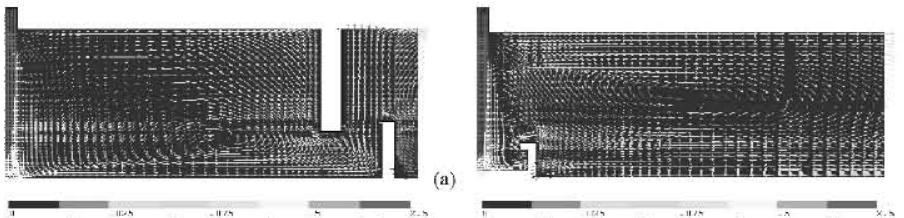

Figura 2. Velocidade resultante no plano de simetria longitudinal, (a) distribuidor atual com barragens e diques, (b) distribuidor com alteração no fundo - tipo elevado (150 mm) e inibidor de turbulência.(2)

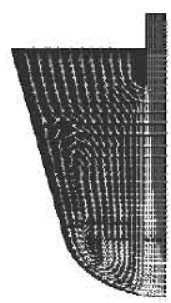

(a)

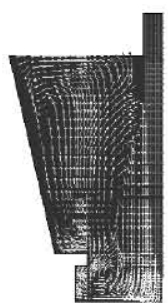

(b)
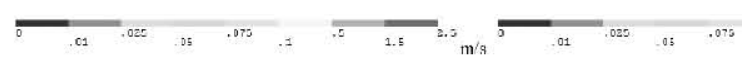

Figura 3. Velocidade resultante no plano de simetria transversal: (a) distribuidor atual com barragens e diques; (b) distribuidor com alteração no fundo - tipo elevado (150 mm) e inibidor de turbulência.(2)

Na Figura 2, que representa um corte no plano de simetria longitudinal, até a região onde estão posicionados os diques e as barragens, pode-se observar a presença de regiôes de recirculação através dos perfis de velocidade obtidos. Além disso, nota-se claramente a alteração das linhas de fluxo no distribuidor atualmente utilizado no processo de lingotamento contínuo da Usiminas [figura 2(a)], quando se utiliza o inibidor de turbulência como dispositivo modificador de fluxo [figura 2(b)].

$O$ inibidor de turbulência é projetado para reorientar o fluxo de aço em direção à superfície livre do distribuidor. Isto evita o escoamento do aço junto ao fundo do distribuidor e que uma parcela deste atinja rapidamente a saída. Essa alteração no perfil de escoamento do aço é facilmente visualizada nas Figuras 2 e 3.

Quando o inibidor de turbulência é empregado, a grande energia cinética, resultante da alta velocidade do aço no fluxo de entrada, é dissipada no interior desse dispositivo, reduzindo a velocidade de escoamento do aço no distribuidor. Para melhor visualização do efeito do confinamento da região de alta velocidade, são apresentados, na Figura 4, os perfis de distribuição da energia cinética de turbulência (k) para algumas configuraçōes estudadas.
A partir dos perfis de velocidade obtidos e da variação da concentração do traçador na saída do distribuidor com o tempo, podem-se obter as curvas de distribuição de tempo de residência (curvas DTR) para as diversas situações simuladas. Estas curvas são determinadas a partir da solução da equação (2).

Após a obtenção da curva DTR para cada situação proposta, são determinados parâmetros importantes utilizados para a avaliação e otimização do escoamento do aço líquido no distribuidor, tais como: tempo de residência médio, tempo de residência mínimo, fração de volume com escoamento em pistão, fraçâo de volume com mistura perfeita e fração de volume morto. A metodologia sugerida por Sahai e $\operatorname{Emi}^{(3)}$ foi adotada na determinação desses parâmetros.

As condiçôes de idealidade do distribuidor devem satisfazer, em princípio, requisitos hidrodinâmicos importantes, tais como: mínimo volume morto, fração elevada de volume pistonado, máxima região de mistura perfeita, mínimo volume de "curtocircuito" e tempos de residência do metal líquido no distribuidor mais elevados. $(2 ; 4-9)$

A Tabela I apresenta uma síntese dos resultados obtidos para cada configuração simulada, onde se avaliam a modificação no fundo do distribuidor do processo de lingotamento contínuo e a utilização do inibidor como um dispositivo controlador de fluxo de aço líquido.

Pode-se observar, a partir da Tabela I, que as modificações no distribuidor (caso I), adotando-se tanto fundos do tipo elevado (casos 2, 3 e 4) quanto os do tipo inclinado (casos 5, 6 e 7), promovem, principalmente, em virtude da diminuição do seu volume útil, uma redução do tempo de residência do aço líquido em seu interior e um aumento das zonas mortas que, por sua vez, poderão comprometer a qualidade final do produto lingotado.
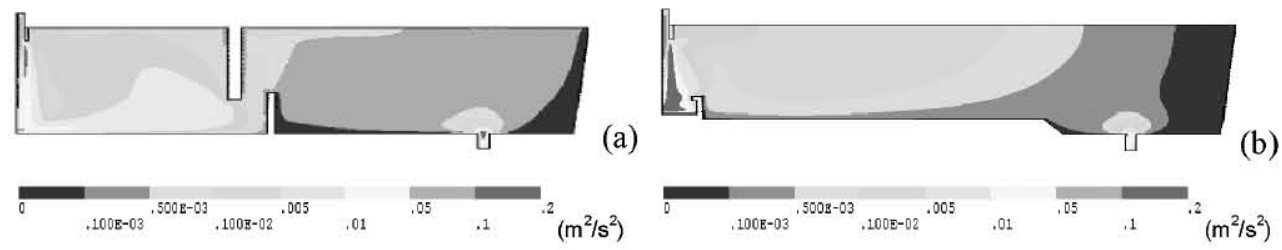

Figura 4. Perfil de distribuiçäo da energia cinética de turbulência $-k$ no plano de simetria longitudinal: (a) distribuidor atual; (b) distribuidor com alteraçäo no fundo - tipo elevado $(150 \mathrm{~mm})$ e inibidor de turbulência.(2) 
Tabela I. Síntese dos resultados obtidos nas diferentes simulaçōes numéricas.

\begin{tabular}{|c|c|c|c|c|c|c|c|c|c|c|}
\hline \multirow{2}{*}{ Parâmetros de escoamento } & \multicolumn{10}{|c|}{ Casos simulados } \\
\hline & I & 2 & 3 & 4 & 5 & 6 & 7 & 8 & 9 & 10 \\
\hline Volume do distribuidor $\left(\mathrm{m}^{3}\right)$ & 41,5 & 39,3 & 38,3 & 37,0 & 40,4 & 39,9 & 39,3 & 40,0 & 39,7 & 39,1 \\
\hline Tempo de residência mínimo (s) & 60,5 & 58,5 & 59,1 & 60,8 & 53,5 & 58,1 & 64,8 & 91,6 & 84,4 & 91,6 \\
\hline Tempo de residência real $(\mathrm{s})$ & 223 & 207 & 163 & 146 & 208 & 201 & 210 & 224 & 257 & 253 \\
\hline Fração de volume morto & 0,221 & 0,236 & 0,381 & 0,427 & 0,251 & 0,267 & 0,226 & 0,187 & 0,061 & 0,058 \\
\hline Fração de volume pistonado & 0,212 & 0,216 & 0,224 & 0,238 & 0,192 & 0,211 & 0,239 & 0,333 & 0,308 & 0,340 \\
\hline Fraçäo de volume de mistura & 0,567 & 0,548 & 0,395 & 0,335 & 0,556 & 0,521 & 0,534 & 0,480 & 0,631 & 0,602 \\
\hline \multicolumn{11}{|l|}{ Descrição dos casos simulados: } \\
\hline \multicolumn{4}{|c|}{ Caso I - figura I.a) } & \multicolumn{7}{|c|}{ Caso 6 - figura I.c) - altura da base $200 \mathrm{~mm}$} \\
\hline \multicolumn{4}{|c|}{ Caso 2 - figura I.b) - altura da base $150 \mathrm{~mm}$} & \multicolumn{7}{|c|}{ Caso 7 - figura I.c) - altura da base $250 \mathrm{~mm}$} \\
\hline \multicolumn{4}{|c|}{ Caso 3 - figura I.b) - altura da base $200 \mathrm{~mm}$} & \multicolumn{7}{|c|}{ Caso 8 - figura I.d) - altura da base $150 \mathrm{~mm}$} \\
\hline \multicolumn{4}{|c|}{ Caso 4 - figura I.b) - altura da base $250 \mathrm{~mm}$} & \multicolumn{7}{|c|}{ Caso 9 - figura l.e) - altura da base $150 \mathrm{~mm}$} \\
\hline \multicolumn{4}{|c|}{ Caso 5 - figura I.c) - altura da base $150 \mathrm{~mm}$} & \multicolumn{7}{|c|}{ Caso 10 - figura I.f) - altura da base $150 \mathrm{~mm}$} \\
\hline
\end{tabular}

Os tempos de residência mínimo e médio obtidos para os distribuidores dotados de inibidor de turbulência e com modificação no fundo (casos 8,9 e 10) são superiores aos resultados al cançados para o distribuidor atualmente em uso (caso I). Além disso, esses projetos de distribuidor apresentam melhores condiçốes de escoamento, pois promovem aumento do tempo de residência médio do aço no interior do distribuidor, redução da fração de volume morto, elevação da fração de volume pistonado e as regiốes de mistura não sofrem grandes variações, quando comparado ao distribuidor atual.

A Tabela I apresenta, também, o efeito proporcionado pela combinação do inibidor de turbulência com as barragens e os diques no escoamento do aço no interior do distribuidor (casos 9 e 10). A utilização do inibidor em conjunto com esses dispositivos aumentou em aproximadamente $25 \%$ o tempo de residência médio, comparando-se os casos 9 e 10 com o distribuidor simulado no caso 2. Além disso, as fraçốes de volume morto reduziram substancialmente $(75 \%)$ e as frações de volume pistonado e de volume de mistura aumentaram consideravelmente $(50 \%$ e $12 \%$, respectivamente).

Assim, a prática de alteração no fundo do distribuidor do lingotamento contínuo tornase viável, baseando-se nos aspectos relativos ao escoamento do aço líquido, se o inibidor de turbulência for incorporado ao seu projeto.

Para a realização dos testes no modelo a frio, simulou-se a mesma condição de lingotamento definida no modelo matemático e avaliaram-se as configuraçōes previstas nos casos I, 2, 8, 9 e 10 (Tabela I). Para cada configuração proposta foram efetuados cinco ensaios. A Figura 5 apresenta os resultados comparativos dos tempos de residência médio entre as experiências realizadas nos modelos fisico e matemático.
Pode-se notar, a partir da Figura 5, que os tempos de residência médios do modelo matemático estão em excelente concordância com os obtidos nos experimentos do modelo físico. Os desvios relativos médios foram inferiores a 6,2\%. Assim, podese afirmar que as experiências realizadas no modelo físico comprovaram que o modelo matemático desenvolvido representou bem os fenômenos físicos presentes no distribuidor. Além disso, a utilização do número de Froude como critério de similaridade para avaliar o escoamento do aço em distribuidores do lingotamento contínuo é bastante eficiente.

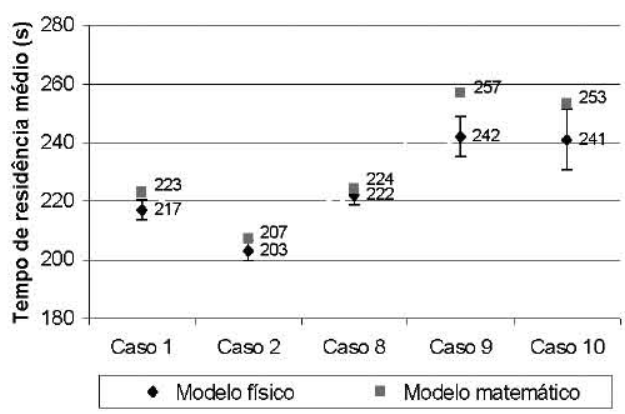

Figura 5. Resultados comparativos dos tempos de residência médio entre as experiências realizadas nos modelos físico e matemático.(2)

\section{CONCLUSÃO}

Um modelo matemático para o escoamento tridimensional turbulento em distribuidores de lingotamento contínuo é desenvolvido e validado, por meio de experiências realizadas em modelo físico, com a finalidade de avaliar os efeitos da modificação no fundo do distribuidor e da utilização do inibidor de turbulência no escoamento do aço líquido. A alteração do distribuidor - adotando-se tanto o fundo do tipo elevado quanto o do tipo inclinado compromete os parâmetros de escoamento do aço em seu interior.

Entretanto, o uso combinado dos dispositivos modificadores de fluxo, diques e barragens, e do inibidor de turbulência permite obter melhores condiçốes de escoamento para o aço, viabilizando a adoção de projetos de distribuidores com fundo elevado os quais, por sua vez, favorecem as operaçōes metalúrgicas nas operações de troca de qualidade lingotada e esgotamento e remoção de aço e de escória em fim de corrida. 


\section{REFERÊNCIAS BIBLIOGRÁFICAS}

I. LAUNDER, B. E.; SPALDING, D. B. The numerical computation of turbulent. Computer Methods in Applied Mechanics and Engineering, v. 3, p. 269-289, 1974.

2. BARBOSA, F. A. Modelamentos matemático e físico do escoamento do aço líquido em diferentes projetos de distribuidor do lingotamento contínuo da Usiminas. 2002. I88f. Dissertação (Mestrado em Engenharia Metalúrgica) - Departamento de Engenharia Metalúrgica e de Minas, Universidade Federal de Minas Gerais, Belo Horizonte, 2002.

3. SAHAI, Y.; EMI, T. Criteria for water modelling of melt flow and inclusion removal in continuous casting tundishes. ISIJ International, v. 36, n. 9, p. I I66-II73, 1996.

4. AHUJA, R.; SAHAI, Y. Fluid flow and mixing of melt in steelmaking tundishes. Ironmaking Steelmaking, v. I3, n. 5, p. 24I-247, 1986.

5. COSTA, J. G. N. Otimização do fluxo de aço no distribuidor de lingotamento contínuo. 1997. 147f. Tese (Doutorado em Engenharia Mecânica) - Departamento de Engenharia de Materiais, Universidade Estadual de Campinas, São Paulo, 1997.

6. GANDRA, C. A. Modelamento físico do fluxo de aço líquido no interior do distribuidor de lingotamento contínuo em regime transiente. 2002. I83f. Dissertação (Mestrado em Engenharia Metalúrgica) - Rede Temática em Engenharia de Materiais, Universidade Federal de Ouro Preto, Ouro Preto, 2002.

7. SILVA, L.G. Modelamento físico no distribuidor do lingotamento contínuo. 1997. I53f. Dissertação (Mestrado em Engenharia Metalúrgica) - PPGEM da Escola de Engenharia da Universidade Federal do Rio Grande do Sul, Porto Alegre, 1997.

8. SINGH, S.; KORIA, S.C. Tundish steel melt dynamics with and without flow modifiers through physical modelling. Ironmaking and Steelmaking, v. 23, n. 3, p. 225-263, 1996.

9. WOLLMANN, A.M. Estudos de fluxo em um distribuidor de lingotamento contínuo. 1999. 93f. Dissertação (Mestrado em Engenharia Metalúrgica) - PPGEM da Escola de Engenharia da Universidade Federal do Rio Grande do Sul, Porto Alegre, 1999. 